Musculoskeletal Care; publisert e-pub ahead November 2017.

DOI:10.1002/msc.1224

\title{
Negative perceptions of illness and health are associated with frequent use of physiotherapy in primary health care
}

Authors: Gro Opseth, ${ }^{1}$ Astrid Klopstad Wahl, ${ }^{2}$ Gustav Bjørke, ${ }^{1}$ Anne Marit Mengshoel ${ }^{2}$

${ }^{1}$ Hans and Olaf Fysioterapi, Oslo, Norway, ${ }^{2}$ Department of Health Sciences, Institute of Health and Society, University of Oslo, Oslo, Norway

Correspondance: Gro Opseth, Hans and Olaf Fysioterapi, Badstugt.2, 0181 Oslo, Norway. Email: gro.opseth@gmail.com

Funding information: Partly supported by the Norwegian Fund for Post-Graduate Training in Physiotherapy through FYSIOPRIM, Project Number 360/90 


\begin{abstract}
Background: There is growing concern that an aging population and increasing number of patients with chronic illnesses in the future will foster a need for health services beyond the resources available in society. Patients with chronic illnesses are reported to be frequent users of physicians' services in the primary health sector. Therapies for patients with chronic musculoskeletal illnesses are delivered by physiotherapists in this sector. However, we know little about the use of physiotherapy services and the factors that may explain their use.
\end{abstract}

Purpose: The aim of the present study is to examine the association between the regular/nonregular use of physiotherapy services, impacts of illness, and perceptions of illness and health.

Method: A cross-sectional survey included patients between 18 and 70 years old who visited a physiotherapy outpatient clinic in Oslo during one randomly chosen week. Patient characteristics and use of physiotherapy were mapped. The Brief Illness Perception Questionnaire (BIPQ), a single item of the SF-12, and the Ørebro Musculoskeletal Pain Questionnaire (ØMPQ) were used to assess perceptions of illness and health and impacts of illness. Data were analysed using independent sample t-tests and logistic regression analysis.

Results: A total of 507 patients with a mean age of 46 (SD 12) years participated; $54 \%$ were regular users of physiotherapy. BIPQ $(\mathrm{p}=0.16, \mathrm{~B}=.030)$ and general health $(\mathrm{p}=0.001, \mathrm{~B}=.444$, were the only significant variables in the final equation associated with regular use of physiotherapy.

Conclusion: About half the sample was regular, high consumers of physiotherapy, and negative perceptions of illness and health were associated with this regular use.

Keywords: Outpatient physiotherapy, physiotherapy attendance, primary health care, musculoskeletal pain 


\section{INTRODUCTION}

In Europe, there is growing concern that an aging population and increasing number of patients with chronic illnesses in the future will foster a need for health services beyond the resources available in society (Horizon, 2020). Services for elderly people and patients with chronic illnesses are mostly delivered within the primary health sector. For example, in Great Britain, about $80 \%$ of the patients who consulted general practitioners (GP) in primary health care had chronic illnesses (Wilson et al., 2005), and a literature review showed that these patients also tended to consult their GPs frequently (Vedsted and Christensen, 2005). However, frequent consultations with GPs are not due exclusively to the severity of illness, but are shown to be associated with patient characteristics (Foster et al., 2006), social factors, psychological distress, multiple physical comorbidities (Dinkel et al., 2016) or mental disorders (Gili et al., 2011). Multiple and complex reasons for why patients tend to frequently consult their GPs are also suggested by a systematic review (Gill and Sharpe, 1999).

Despite concern about the high future need of health services in primary health care, little attention has been paid to the use of physiotherapy in this sector. Musculoskeletal pain conditions are a frequent complaint in the general population (Ihlebaek et al., 2002; Ihlebaek and Laerum, 2010), and self-reported musculoskeletal pain is found to predict use of services from physiotherapists, chiropractors and GPs in primary health care (Hartvigsen et al., 2014). A Dutch study showed that almost all patients referred to physiotherapy had complaints related to the musculoskeletal system, and about one-third had complaints lasting for more than one year (Hendriks et al., 2003b). Moreover, another study reported that those receiving physiotherapy in primary health care in the USA, Israel and the Netherlands were predominantly of working age, under treatment for low back pain, and suffering from subacute or persistent pain (Swinkels et al., 2008). This indicates that persistent pain and its impact on health are likely to be reasons why patients consult physiotherapists in primary health care.

Few studies have examined the number of consultations of physiotherapy used by patients in primary health care. Based on estimates from registries in different countries, it was reported that the mean number of physiotherapy sessions per treatment episode for a patient in the USA was 10.2, in Israel 6.4 and in the Netherlands 12.5 (Swinkels et al., 2008). Another Dutch study, however, showed that about $50 \%$ of those attending physiotherapy were prior users of physiotherapy (Hendriks et al., 2003b). This raises the question of how frequent such episodes of physiotherapy actually are. Previously we have reported that there are large numbers of patients who are regular users of physiotherapy, and there were small, but statistically significant differences between regular and non-regular users with respect to patient characteristics, employment status and pain duration. Moreover, both groups tended to be high users of medical specialists, other health professionals and various radiological examinations (Opseth et al., 2014). To the best of our knowledge, no prior studies have yet examined what may explain why patients become frequent users of physiotherapy. Thus, the objective of this study is to examine the association between the regular/non-regular use of physiotherapy services, impacts of illness, and perceptions of illness and health. 


\section{METHOD AND MATERIALS}

\subsection{Context, design and recruitment}

The present study is part of a cross-sectional survey conducted during one randomly chosen week among patients who attended an outpatient physiotherapy clinic in the centre of the capital city of Norway. The clinic is part of the primary health sector, and the costs of services are fully or partly covered by health authorities. The clinic employs 32 physiotherapists, and 27 were engaged in consecutively recruiting their patients for the study during the week of data collection. Among those, 17 were senior manual therapists and 8 students in manual therapy. All but one senior manual therapist had the authority to deliver services without a doctor's referral, refer patients to medical specialists and radiological examinations, as well as being authorized to prescribe sick notes. Inclusion criteria for participating in the study were that the patients had to be adults that could be expected to be engaged in education or paid work; hence we included patients between 18 and 70 years of age. In addition, they had to be fluent in spoken and written Norwegian. Those volunteering to participate received a booklet of questionnaires from their physiotherapists. The questionnaires were filled in at the clinic or at home and returned in a sealed envelope to either their physiotherapist or the outpatient clinic's receptionist, or sent by post to the researchers. Of the 619 questionnaires handed out, 562 were returned (91\%). Of these, 55 participants were over 70 years old and were excluded.

\subsection{Ethical considerations}

The study was approved by the Regional Committee for Medical Research Ethics. Written information about the purpose of the study and voluntary participation was given by the physiotherapists. The patients were told that their decision whether or not to participate had no consequences for their treatment and that their physiotherapists would have no access to their responses to the questionnaires. The physiotherapists also handed out the questionnaires and a prepaid envelope for returning the questionnaire to secure anonymity.

\subsection{Questionnaires}

\subsubsection{Patient characteristics and use of physiotherapy}

Demographic variables included items about age, gender, education level, and employment status. Patients were also asked, 'How often do you see your physiotherapist, and are you using physiotherapy regularly or not?' We also included a question about whether their reason to attend physiotherapy was to be cured, become somewhat better, or to avoid becoming worse. The questionnaire was pilot-tested on 10 patients and adjusted based on their feedback.

\subsubsection{The Ørebro Musculoskeletal Pain Questionnaire (ØMPQ)}

The ØMPQ was used to assess the impacts of illness. The ØMPQ is a thoroughly tested, selfadministered screening instrument developed for clinical use (Boersma and Linton, 2005; Grotle et al., 2007; Grotle et al., 2006; Linton and Hallden, 1998). Guidelines from Australia, New Zealand and Norway recommend the use of the ØMPQ to identify patients at risk of developing persistent pain conditions and work absence in the future (Group, 2003; Huang, 
1997; FORMI, 2014). We applied a Norwegian version of the ØMPQ that was translated and tested for feasibility by Grotle et al. (Grotle et al., 2006).

The ØMPQ includes 25 questions; the first four items ask for the patient's demographics, and the next 21 items are included in the calculation of a total score of illness impacts. These questions include nine items concerning pain (locations, duration, intensity last week and last three months, episodes of acute pain, pain coping, perception of risk of chronicity, activityinduced pain, fear avoidance belief), one item about sleep problems, two items about psychological problems (depression, anxiety and tension), four items about performing specific daily activities, five items about work (work absence, heavy or monotonous work, work satisfaction, future work expectation) (Linton and Hallden, 1998). The severity of the problem is ranked on a numerical scale from 0-10. Of the 21 items in the ØMPQ, missing responses to four items was the maximum regarded as acceptable. In 37 cases, the missing scores were replaced by an average score of the individual's other scores. A sum score was calculated with a possible range from 0 to 210 , where the higher the score, the more severe illness impacts (Linton and Hallden, 1998).

\subsubsection{The Brief Illness Perception Questionnaire (BIPQ)}

The BIPQ assessed the patients' cognitive perception and attitudes towards their illness (Broadbent et al., 2006). The questionnaire includes eight items addressing the following areas: Consequences (item 1), timeline (item 2), personal control (item 3), treatment control (item 4), condition and symptoms (item 5), coherence (item 7), and concerns and emotions (item 6 and 8). The responses were rated on a numerical scale from 0-10. A total score, ranging from 0 to 80 , was calculated according to guidelines described at www.uib.no/ipq/index.html. A high score expressed more negative illness perception.

\subsubsection{Short Form Health Survey (SF 12)}

The SF 12 is a health-related quality of life questionnaire found to be valid and reliable, including items related to mental and physical health (Ware, 1996). In the present study, we applied one single item that addresses an evaluation of general health: 'In general, what is your health like?' assessed on an ordinal scale with 5 alternatives from bad to excellent. Applying a single item has been found to be valid and reliable as multi-item scales (de Boer et al., 2004).

\subsection{Statistical analysis}

The statistical program IBM SPSS Statistics version 24 was utilized in the analyses of the data. Descriptive categorical data are presented in numbers and percentages. The continuous data are presented as mean and standard deviation (SD). The sample was divided into two groups on the basis of their response to the question about regular or non-regular attendance of physiotherapy. Differences between groups were analysed by the two-sample t-test for continuous variables and the Chi-squared test for categorical variables. Binary logistic regression analysis was carried out in four blocks in order to analyse the associations between regular and non-regular users of physiotherapy (dependent variable), and age, gender, 
education, the total scores of the ØMPQ and the BIPQ, as well as the single item about general health (independent variables). The correlations between the independent variables did not reach 0.70 , indicating less chance of multicollinearity. Possible interaction effects between independent variables and the dependent variable were also analysed with logistic regressions. Due to missing data in the different variables included in the regression equations, the final sample analysed was 437. Statistical significance level was set at $p \leq 0.05$.

\section{RESULTS}

\subsection{Patient characteristics, pain and use of physiotherapy (regular/non-regular users)}

The present sample comprised 507 patients, and their characteristics are shown in Table 1. Their mean age was 46 years. Everyone reported pain locations in one or more sites of the body, and $83 \%$ had been suffering from pain for more than three months. Fifty-four percent reported to be regular users of physiotherapy. Among the regular users, 93\% reported that they visited their physiotherapist once every second week or more, while $7 \%$ came once every fourth week or less. In the non-regular user group, $29 \%$ had low expectations of becoming pain-free from physiotherapy compared to $60 \%$ among the regular users $(\mathrm{p}<0.001)$. Among the regular users of physiotherapy, $94 \%$ had pain duration more than one year compared to $41 \%$ among non-regular users $(\mathrm{p}<0.001)$. Regular users were more often not working and had higher scores on the ØMPQ, BIPQ and general health than the non-regular users of physiotherapy.

\subsection{Use of physiotherapy, health-related impacts, and perceptions of illness and health}

With regard to the association between selected socio-demographic variables and regular use of physiotherapy, age was the only significant variable $(\mathrm{p}=0.004, \mathrm{~B}=.002)$ in the first block (independent variables: age, gender and education), indicating that regular users of physiotherapy are older than non-regular users (see Table 2). The first block explained 3\% of the variance in the use of regular/non-regular physiotherapy.

When adding ØMPQ (second block), the age difference disappeared, and the only significant variable was the $\varnothing \mathrm{MPQ}(\mathrm{p}=0.000, \mathrm{~B}=.020)$, indicating that regular users of physiotherapy report more musculoskeletal-related health impacts than non-regular users of physiotherapy (independent variables: block1 $+\varnothing \mathrm{MPQ}$ ). The second block explained $12 \%$ of the variance in use of regular/non-regular physiotherapy.

In the third block BIPQ was added to the equation (independent variables: block $1,2+$ $\mathrm{BIPQ})$, and for this model age $(\mathrm{p}=0.02 ; \mathrm{B}=.02), \varnothing \mathrm{MPQ}(\mathrm{p}=0.047, \mathrm{~B}=.01)$, and BIPQ $(\mathrm{p}=0.001, \mathrm{~B}=.04)$ were all significant, although the statistical significance of ØMPQ became weaker. The association between BIPQ and use of physiotherapy indicates that a more negative attitude towards illness is associated with being a regular user of physiotherapy. This equation explained $15 \%$ of the variance in use of regular/non-regular physiotherapy.

The final model (block 4) included all variables in block 1-3, and in addition the single item of perceived general health status. BIPQ $(\mathrm{p}=0.02, \mathrm{~B}=.03)$ and general health $(\mathrm{p}=0.001, \mathrm{~B}=.44)$ were the only significant variables in the final equation, indicating that a perception of worse 
general health is associated with being a regular user of physiotherapy. ØMPQ did not reach statistical significance in the final model $(\mathrm{p}=0.46, \mathrm{~B}=.004)$. Eighteen percent of the variance in use of physiotherapy was explained by this model.

No significant interaction effects were found between independent variables on the associations with the dependent variable (use of physiotherapy).

\section{DISCUSSION}

A total of 507 patients participated in the present study, and 54\% were regular users of physiotherapy. Low self-reported general health and a negative attitude towards illness were associated with being a regular user of physiotherapy.

Those frequently consulting GPs are often suffering from chronic illnesses (Vedsted and Christensen, 2005). In our sample, $83 \%$ of the total sample had persistent pain. This aligns with the study showing that the majority of patients treated by physiotherapists in the USA and Israel had persistent pain conditions, in contrast with the report of only $35 \%$ in the Netherlands (Swinkels et al., 2008). The high number of patients with persistent musculoskeletal pain conditions attending physiotherapy may be due to the Norwegian system of funding physiotherapy services in the primary health sector; when a certain cost level is reached, the services are fully covered by official health budgets. Our study showed that despite having persistent musculoskeletal pain, the majority of patients managed to continue working. Thus, the high use of physiotherapy can be an acceptable cost to enable patients to remain in the workforce. Moreover, evidence-based guidelines recommend lifestyle changes and exercise to these patients (Childs et al., 2008; Harris and Susman, 2002, Ottawa Panel 2005). One may argue that this could be delivered more efficiently by physiotherapists than in time-limited GP consultations, as well as reduce the cost of similar interventions delivered by secondary or tertiary health care. Therefore, this might be an appropriate way to organize services to patients with long-lasting musculoskeletal pain conditions, but this calls for largescale cost-effectiveness studies.

About half of the respondents reported frequent use of physiotherapy. This finding corresponds to some extent with the Dutch study which reported that about half of the patients in physiotherapy treatment at the time of the study had seen a physiotherapist previously (Hendriks et al., 2003a). However, our study revealed that the patients did not only have prior experience with physiotherapy, but also reported a high number of consultations during both last year and the past five years (data not shown). Thus, in addition to being regular users, the estimates of physiotherapy use over a time span suggest that these patients were regular, longtime consumers of physiotherapy services in the primary health sector. Such a pattern might be concealed in the prior cross-cultural study in which only the number of sessions per treatment episode was assessed (Swinkels et al., 2008).

Presently, the high percent of regular users was rather surprising, especially because the majority of the physiotherapists were manual therapists whose specialized therapeutic skills are predominantly applied to acute or subacute conditions. A high number of the manual therapists also had the authority to deliver services directly to patients without a referral from a physician. This suggests that there should be a high number of short-term pain conditions similar to a study from the Netherlands in which the implementation of a patient self-referral 
system showed an increase in the proportion of patients with acute and subacute pain conditions seen by physiotherapists (Swinkels et al., 2014). However, the Dutch study did not calculate whether this was also accompanied by fewer physiotherapy consultations per patient. Presently, the high number of regular users may be due partially, but not solely, to this particular institute's good reputation for treating patients, thus becoming a sort of last referral attempt by the GPs when other physiotherapists have failed. In support of this notion is that the regular, long-time users of physiotherapy were also high consumers of other health services both in the primary and specialized health care sector (Opseth et al., 2014). This raises a critical question whether the presently high use of health services by patients with long-lasting musculoskeletal pain conditions is appropriate. On the other side, patients and physiotherapists probably have several reasons for continuing their treatments. Thus, qualitative studies exploring patients' and physiotherapists' treatment experiences are needed.

The regular users of physiotherapy had more frequently persistent pain, fewer were working, the impact of their illness was more severe, and their illness was perceived as more threatening than by the group of non-regular physiotherapy users. As the ØMPQ is claimed to assess psychosocial factors (Westman et al., 2008), these findings may correspond to high levels of psychosocial problems found among those attending GPs regularly (Dinkel et al., 2016). Strikingly, in the regression model we found that self-reported poor health and negative attitudes towards illness were associated more with being regular users than with the impacts of illness. This suggests that an important reason for regular use of physiotherapy is negative beliefs about health and illness. This indicates that these patients are what the GPs call the 'heart-sink' patients, whom doctors seem to refer to physiotherapy to minimize their own stress or to share the burden with the physiotherapists (Clemence and Seamark, 2003). However, studies have shown that physiotherapists rely on a biomedical-oriented way of thinking and lack education in dealing with psychological issues (Lederman, 2011; Sanders et al., 2013; Singla et al., 2015). Thus, physiotherapists need to be trained in how to address patients' negative beliefs. Another solution might be that physiotherapists or GPs learn to identify this particular challenge and either send them to professionals who are more competent in dealing with this issue and that physiotherapists collaborate closely with such personnel. It might be that this is a particular group of patients with chronic illness that needs a more complex, multidisciplinary approach. Hence, a close collaboration between GPs, physiotherapists and other health professionals to create new insights and approaches to enable patients to manage their own illness without continuous support by health professionals would probably ease the challenge for both parties and promote better care for the patients. This calls for systematic developmental work that in turn should impact the educational curriculums for physiotherapists.

The present study has strengths and limitations. First, a cross-sectional design does not allow us to find out who is at risk of becoming a regular user of physiotherapy, but merely to examine associations to identify probable contrasting patterns in the two user groups. The validity of our findings relies heavily on whether we can trust how patients classified themselves as regular users or not. Taking into consideration the response to the item on the participants' evaluation about being a regular user, the patients' classification of regular use was highly supported by their report of a high number of physiotherapy consultations over time. This correspondence makes us rather confident in the validity of the classification of groups. The chosen instruments are well tested and tried out, and we consider them to be appropriate for the purpose of our study. The methodological strengths are our high sample size in the groups, high response rate and low number of missing data. There is no indication that the patients included during the one week survey differed from those who usually attend the clinic. It is therefore likely that the participants in the study are reasonably representative 
of the clinic, and we do not think that this clinic differs too much from other private physiotherapy clinics with official financial support in Norway, at least within urban areas. However, organization of primary health services across countries may differ, as suggested by the Dutch study (Swinkels et al., 2014).

In conclusion, about half of the present sample was regular users of physiotherapy, and negative perceptions of health and illness were associated with regular use. This suggests that for these patients, physiotherapists must take into consideration and approach patients' negative beliefs related to their own health and illness to optimize their treatment. There is limited research about the use of primary health services, and although future studies are needed to verify or dispute our findings, our results should lead to discussions among health professionals and stakeholders in primary health care.

\section{REFERENCES}

Boersma, K. and Linton, S.J. (2005) Screening to identify patients at risk: profiles of psychological risk factors for early intervention. The Clinical journal of pain 21, 38-43; discussion 69-72.

Broadbent, E., Petrie, K.J., Main, J. and Weinman, J. (2006) The brief illness perception questionnaire. Journal of psychosomatic research 60, 631-637.

Childs, J.D., Cleland, J.A., Elliott, J.M., Teyhen, D.S., Wainner, R.S., Whitman, J.M., Sopky, B.J., Godges, J.J. and Flynn, T.W. (2008) Neck pain: Clinical practice guidelines linked to the International Classification of Functioning, Disability, and Health from the Orthopedic Section of the American Physical Therapy Association. The Journal of orthopaedic and sports physical therapy 38, A1-a34.

Clemence, M.L. and Seamark, D.A. (2003) GP referral for physiotherapy to musculoskeletal conditions--a qualitative study. Fam Pract 20, 578-582.

de Boer, A.G., van Lanschot, J.J., Stalmeier, P.F., van Sandick, J.W., Hulscher, J.B., de Haes, J.C. and Sprangers, M.A. (2004) Is a single-item visual analogue scale as valid, reliable and responsive as multiitem scales in measuring quality of life? Quality of life research : an international journal of quality of life aspects of treatment, care and rehabilitation 13, 311-320.

Dinkel, A., Schneider, A., Schmutzer, G., Brahler, E. and Hauser, W. (2016) Family physician-patient relationship and frequent attendance of primary and specialist health care: Results from a German population-based cohort study. Patient education and counseling 99, 1213-1219.

FORMI (2014). FORMI: Communication- and research unit for musculoskeletal disorders, Division for neuroscience and musculoskeletal medicine. Oslo University Hospital., www.formi.no.

Foster, A., Jordan, K. and Croft, P. (2006) Is frequent attendance in primary care disease-specific? Fam Pract 23, 444-452.

Gili, M., Luciano, J.V., Serrano, M.J., Jimenez, R., Bauza, N. and Roca, M. (2011) Mental disorders among frequent attenders in primary care: a comparison with routine attenders. The Journal of nervous and mental disease 199, 744-749.

Gill, D. and Sharpe, M. (1999) Frequent consulters in general practice: a systematic review of studies of prevalence, associations and outcome. Journal of psychosomatic research 47, 115-130. 
Grotle, M., Brox, J.I., Glomsrod, B., Lonn, J.H. and Vollestad, N.K. (2007) Prognostic factors in firsttime care seekers due to acute low back pain. European journal of pain (London, England) 11, 290 298.

Grotle, M., Vollestad, N.K. and Brox, J.I. (2006) Screening for yellow flags in first-time acute low back pain: reliability and validity of a Norwegian version of the Acute Low Back Pain Screening Questionnaire. The Clinical journal of pain 22, 458-467.

Group, A.A.M.P.G. (2003) Evidence-based management of acute musculoskeletal pain., Australian Academic Press, Browen Hills.

Harris, G.R. and Susman, J.L. (2002) Managing musculoskeletal complaints with rehabilitation therapy: summary of the Philadelphia Panel evidence-based clinical practice guidelines on musculoskeletal rehabilitation interventions. The Journal of family practice 51, 1042-1046.

Hartvigsen, J., Davidsen, M., Sogaard, K., Roos, E.M. and Hestbaek, L. (2014) Self-reported musculoskeletal pain predicts long-term increase in general health care use: a population-based cohort study with 20-year follow-up. Scandinavian journal of public health 42, 698-704.

Hendriks, H.J.M., Kerssens, J.J., Heerkens, Y.F., Elvers, J.W.H., Dekker, J., van der Zee, J. and Oostendrop, R.A.B. (2003b) Referral patterns and utilization of physiotherapy services following a one-time physiotherapist consultation in general practice. Physiotherapy Theory and Practice 19, 521.

Horizon 2020, EU. https://ec.europa.eu/programmes/horizon2020/en/h2020-section/healthdemographic-change-and-wellbeing

Huang, G. (1997) Book Review Guide to Assessing Psychosocial Yellow Flags in Acute Low Back Pain: Risk Factors for Long-Term Disability and Work Loss. Kendall NAS, Linton SJ, Main CJ. Wellington, New Zealand: Accident Rehabilitation \& Compensation Insurance Corporation of New Zealand and the National Health Committee, 1997, 22 pp. Public Domain, New York, pp. 249-250.

Ihlebaek, C., Eriksen, H.R. and Ursin, H. (2002) Prevalence of subjective health complaints (SHC) in Norway. Scandinavian journal of public health 30, 20-29.

Ihlebaek, C. and Laerum, E. (2010) [Hits most, costs most and gets least]. Tidsskrift for den Norske laegeforening : tidsskrift for praktisk medicin, ny raekke 130, 2106.

Lederman, E. (2011) Re: The Fall of the postural-structural-biomechanical model in manual therapy: exemplified by lower back pain. A response to reviewers and further thoughts. Journal of bodywork and movement therapies 15, 257-258.

Linton, S.J. and Hallden, K. (1998) Can we screen for problematic back pain? A screening questionnaire for predicting outcome in acute and subacute back pain. The Clinical journal of pain 14, 209-215.

Opseth, G., Wahl, A.K., Bjørke, G. and Mengshoel, A.M. (2014) Bruk og brukere av fysioterapi i privat praksis/Use and users of physiotherapy in an outpatient practice in primary health. Fysioterapeuten 9/14.

Ottawa panel evidence-based clinical practice guidelines for therapeutic exercises and manual therapy in the management of osteoarthritis (2005). Physical therapy 85, 907-971. 
Sanders, T., Foster, N.E., Bishop, A. and Ong, B.N. (2013) Biopsychosocial care and the physiotherapy encounter: physiotherapists\&\#8217; accounts of back pain consultations.(Research article). BMC musculoskeletal disorders 14, 65 .

Singla, M., Jones, M., Edwards, I. and Kumar, S. (2015) Physiotherapists' assessment of patients' psychosocial status: Are we standing on thin ice? A qualitative descriptive study. Manual therapy 20, 328.

Swinkels, I.C., Hart, D.L., Deutscher, D., van den Bosch, W.J., Dekker, J., de Bakker, D.H. and van den Ende, C.H. (2008) Comparing patient characteristics and treatment processes in patients receiving physical therapy in the United States, Israel and the Netherlands: cross sectional analyses of data from three clinical databases. BMC health services research 8, 163.

Swinkels, I.C., Kooijman, M.K., Spreeuwenberg, P.M., Bossen, D., Leemrijse, C.J., van Dijk, C.E., Verheij, R., de Bakker, D.H. and Veenhof, C. (2014) An overview of 5 years of patient self-referral for physical therapy in the Netherlands. Physical therapy 94, 1785-1795.

Vedsted, P. and Christensen, M.B. (2005) Frequent attenders in general practice care: a literature review with special reference to methodological considerations. Public health 119, 118-137.

Ware Jr, J.E. (1996) A 12-Item Short-Form Health Survey: construction of scales and preliminary tests of reliability and validity. Medical care 34, 220.

Westman, A., Linton, S.J., Ohrvik, J., Wahlen, P. and Leppert, J. (2008) Do psychosocial factors predict disability and health at a 3-year follow-up for patients with non-acute musculoskeletal pain? A validation of the Orebro Musculoskeletal Pain Screening Questionnaire. European journal of pain (London, England) 12, 641-649.

Wilson, T., Buck, D. and Ham, C. (2005) Rising to the challenge: will the NHS support people with long term conditions? BMJ (Clinical research ed.) 330, 657-661. 
Table 1. Demographic variables for patients in physical therapy with between-group comparison

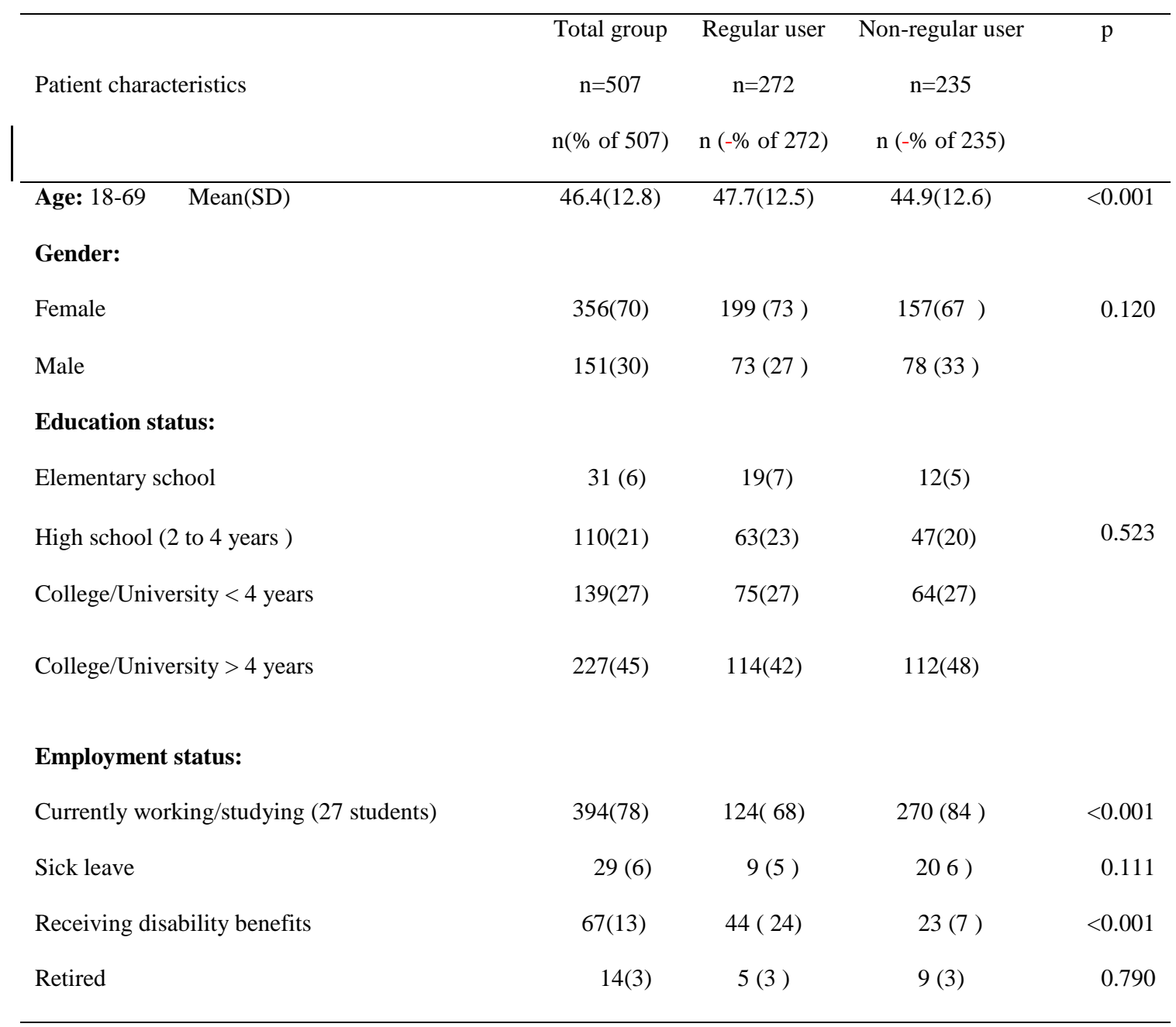

Categorical data are presented in number and \%. Chi-squared test are used to compare categorical data. $\mathrm{P}^{*} \leq 0.05$ 
Table 2: The associations (binary logistic regressions with 4 blocks) between demographic variables, perceptions of health and illness (ØMPQ, BIPQ, single item general health) and regular use of physiotherapy $(n=437)$

\begin{tabular}{|c|c|c|c|c|}
\hline & \multicolumn{4}{|c|}{ Regular use (1) and Non--regular use of physiotherapy (0) } \\
\hline & $\begin{array}{l}\text { Block } 1 \\
\text { Beta (p-values) }\end{array}$ & $\begin{array}{l}\text { Block } 2 \\
\text { Beta (p-values) }\end{array}$ & $\begin{array}{l}\text { Block } 3 \\
\text { Beta (p-values) }\end{array}$ & $\begin{array}{l}\text { Block } 4 \\
\text { Beta (p-values) }\end{array}$ \\
\hline Age (years) & $.02(.04)$ & $.02(.05)$ & $.02(.02)$ & $.02(.06)$ \\
\hline $\begin{array}{l}\text { Gender }(1=\text { men; } \\
2=\text { women })\end{array}$ & $-.36(.09)$ & $-.26(.24)$ & $-.32(.16)$ & $-.31(.17)$ \\
\hline $\begin{array}{l}\text { Education (1-4; higher } \\
\text { score=higher level of } \\
\text { education }\end{array}$ & $\begin{array}{l}\operatorname{Ref}(.73) \\
.39(.37) \\
.14(.58) \\
.20(.40)\end{array}$ & $\begin{array}{l}\operatorname{Ref}(.81) \\
-.39(.41) \\
-.14(.64) \\
.04(.86)\end{array}$ & $\begin{array}{l}\operatorname{Ref}(.93) \\
-.30(.55) \\
-.05(.86) \\
.03(.90)\end{array}$ & $\begin{array}{l}\operatorname{Ref}(.84) \\
-.43(.39) \\
-.06(.84) \\
.03(.91)\end{array}$ \\
\hline $\begin{array}{l}\text { ØMPQ (higher } \\
\text { scores=higher } \\
\text { disability) }\end{array}$ & & $.02(.000)$ & $.01(.047)$ & $.004(.46)$ \\
\hline $\begin{array}{l}\text { BIPQ (higher scores }= \\
\text { higher perceived illness } \\
\text { threat }\end{array}$ & & & $.04(.001)$ & $.03(.02)$ \\
\hline $\begin{array}{l}\text { Single item general } \\
\text { health perception }(1-5 \text {; } \\
\text { higher score=worse } \\
\text { health) }\end{array}$ & & & & $.44(.001)$ \\
\hline Nagelkerke R square & $3 \%$ & $12 \%$ & $15 \%$ & $18 \%$ \\
\hline
\end{tabular}

